\title{
VOLATILITY, INVESTMENT AND DISAPPOINTMENT AVERSION
}

\author{
Joshua Aizenman \\ Nancy Marion
}

Working Paper 5386

\section{NATIONAL BUREAU OF ECONOMIC RESEARCH 1050 Massachusetts Avenue \\ Cambridge, MA 02138 \\ December 1995}

This paper is part of NBER's research program in International Trade and Investment. Any opinions expressed are those of the authors and not those of the National Bureau of Economic Research.

(c) 1995 by Joshua Aizenman and Nancy Marion. All rights reserved. Short sections of text, not to exceed two paragraphs, may be quoted without explicit permission provided that full credit, including $\odot$ notice, is given to the source. 


\title{
VOLATILITY, INVESTMENT AND \\ DISAPPOINTMENT AVERSION
}

\begin{abstract}
This study uncovers a statistically significant negative correlation between volatility and private investment over the 1970-93 period in a set of almost fifty developing countries and provides a possible interpretation of this result by using the disappointment-aversion expected utility framework first described by Gul (1991). We consider a number of different volatility measures related to domestic policies or to external factors. As the various volatility measures tend to be positively correlated, we do not claim to identify a unique measure as the dominant source of volatility. Instead, we demonstrate that for a number of different measures, volatility reduces private investment in developing countries. We then show that the disappointmentaversion framework provides a useful way of illustrating the adverse first-order effects of volatility. When agents are disappointment-averse, they put more weight on "bad" outcomes and less weight on "good" outcomes than in the standard case. The asymmetric weighting of outcomes introduces additional concavity into the utility function and causes volatility to have significant, negative effects on economic performance. The large, negative effects of increased volatility continue to hold even if the coefficient of relative risk aversion approaches zero (that is, even if the marginal utility of income is constant so that agents are risk neutral in the conventional sense).
\end{abstract}

Joshua Aizenman

Department of Economics

6106 Rockefeller Hall

Dartmouth College

Hanover, NH 03755

and NBER
Nancy Marion

Department of Economics

6106 Rockefeller Hall

Dartmouth College

Hanover, NH 03755 


\section{Volatility, Investment, and Disappointment Aversion}

\section{Introduction}

The impact of uncertainty on economic performance has been a topic of obvious concern to policymakers. It has also been the focus of much theoretical research. The research findings are mixed. Some studies suggest that increased uncertainty does not have a major impact on economic performance and conclude that the gains from reducing uncertainty may be small relative to the costs. In their study of commodity price stabilization schemes, for example, Newbery and Stiglitz (1981) show that the increase in expected utility from reduction in price volatility may be of second-order importance for reasonable parameter values. 1 Other studies have questioned whether increased uncertainty necessarily has an adverse impact on economic performance. For example, Hartman (1972) and Abel $(1983,1984,1985)$ have found conditions under which meanpreserving increases in price volatility raise investment spending. Caballero (1991, page 286) has stated that "the relationship between changes in price uncertainty and capital investment under risk neutrality is not robust. ... it is very likely that it will be necessary to turn back to risk aversion, incomplete markets, and lack of diversification to obtain a sturdier negative relationship between investment and uncertainty." 2

It is noteworthy that the major studies on the relationship between uncertainty and economic performance all rely on the standard expected utility paradigm formulated by Savage

1 Also see Pratt (1964). In principle, volatility and uncertainty are different phenomena. Volatility refers to the tendency of a variable to fluctuate, while uncertainty is present only when those fluctuations are unpredictable. In practice, volatile variables are generally unpredictable. We use the two concepts interchangeably.

2For further discussion and references see, for example, Pindyck and Solimano (1993), and Dixit and Pindyck (1994). 
(1954). An important feature of this framework is that the loss of expected utility from increased income volatility is proportional to the variance of income. Consequently, volatility may have rather small effects under reasonable assumptions about the distribution of shocks. These theoretical findings are hard to reconcile with a growing body of empirical work that shows volatility having large, negative effects on investment and growth. 3

The purpose of this paper is to show that volatility can have negative, first-order effects on investment when agents maximizing expected utility attach more weight to "bad" outcomes than to “good" outcomes. Gul (1991) developed this “disappointment-aversion” utility framework in order to rationalize a seemingly paradoxical response of agents to two pairs of gambles (the Allias paradox). We provide a simplified version of this framework and show that it can deliver results consistent with the empirical findings.

The disappointment-aversion framework has several attractive features for our purposes. It is a one-parameter extension of the standard neoclassical expected utility framework. Indeed, it admits the standard expected utility approach as a special case. As a result, it allows one to assess the impact of volatility on investment when agents are disappointment averse relative to the case where they are not. The disappointment-aversion framework is also appealing because it helps explain patterns of individual behavior in various controlled experiments. ${ }^{4}$ At the aggregate level, the framework is also consistent with the empirical evidence that volatility has significant,

${ }^{3}$ Constructed measures of volatility are negatively, and significantly, correlated with real per capita GDP growth rates and with the share of GDP devoted to investment in Barro-type (Barro, 1991) regressions. See Aizenman and Marion (1993) for the negative effects of fiscal, monetary, and inflation volatility measures on investment and growth rates, and Hausmann (1994) for the negative effects of terms-of-trade volatility. Ramey and Ramey (1994) uncover a strong negative relationship between real GDP volatility and the average growth rate of GDP. See Hausmann and Gavin (1995) for a comprehensive overview of the detrimental effects of volatility on investment and growth.

${ }^{4}$ See Harless and Camerer (1994) and Epstein (1992) for further discussion and references. 
negative effects on investment. Even if the marginal utility of income is constant (so that agents are risk neutral in the conventional sense), disappointment aversion provides a mechanism for volatility to affect economic performance adversely.

The paper is organized as follows. Section 2 relies on recently available data in order to update past work on the empirical link between volatility and investment. The empirical evidence reinforces the view that various types of volatility measures are negatively, and significantly, correlated with investment. Section 3 presents a simplified model of the disappointment-averse agent postulated by Gul. The model allows us to measure the cost of volatility when agents are disappointment-averse relative to the standard neoclassical case. Section 4 considers a disappointment-averse investor facing volatility in the form of productivity shocks and shows that this volatility leads to first-order effects on investment. Section 5 concludes. 


\section{The Stylized Facts}

In this section we present evidence of a significant negative correlation between volatility and private investment in a cross-section of developing countries over the 1970-93 period. Past studies have used investment data only up to 1985 , so the data we use encompass eight additional years. In order to obtain country measures of private investment as a share of GDP over the 1970-93 period, we use World Bank annual data that was constructed for a sample of almost fifty developing countries. (Glen and Sumlinski, 1995; Madarassy and Pfeffermann, 1992).

Volatility measures are constructed from annual data by calculating standard deviations from mean values for variables already expressed in rates of change. For variables expressed in levels, the standard deviations of the residuals are calculated from first-order autoregressive processes. 5

Our volatility measures include the volatility of government consumption expenditures as a percentage share of GDP (GOV) and the volatility of government budget deficits as a percentage share of GDP (DEF). In addition, we consider volatility in percentage nominal money growth (M1G), the percentage CPI inflation rate (INF), the percentage change in the real exchange rate (RER) and the percentage change in the terms-of-trade (TOT). We also obtain a measure of the volatility of percentage real per capita GDP growth (GGDP).

Table 1 displays the simple correlations between private investment shares and various volatility measures. In all cases there is a negative correlation between volatility and private investment and in the majority of cases the correlation is highly significant.

We next examine the partial correlation between volatility and private investment while controlling for additional relevant variables. Many investigators have used explanatory variables such as initial real GDP per capita, initial school enrollments, fiscal policy indicators, monetary policy indicators, trade measures, and political indices in an attempt to establish a statistically

${ }^{5}$ The one exception to the rule is the volatility measure for nominal money growth, which is calculated from an AR1 process. 
significant relationship between investment and a particular variable in cross-section data. But as Levine and Reneult (1992) have forcefully pointed out, the results of these cross-section regressions are fragile to small changes in the conditioning information set. Indeed, Levine and Reneult find that only the positive partial correlation between the share of (total) investment in GDP and the share of trade in GDP is robust to small changes in the list of independent variables. We thus consider a cross-section regression where the dependent variable is the average share of private investment in GDP over the 1970-93 period and the independent variables are the average share of trade (exports plus imports) in GDP over the period(OPEN), the level of real GDP per capita in 1970 (RGDP70), the primary-school enrollment rate in 1970 (prim70), an index of political instability based on the number of revolutions and coups (REVCOUP), and a particular measure of volatility. Volatility measures are entered into the regression sequentially since many of them are highly positively correlated as indicated in Table 2.

Table 3 shows the regression results. Because heteroskedasticity may be important across developing countries, the standard errors for the coefficients are based on White's (1980) correction method. The results show a negative relationship between volatility and private investment in all cases. Moreover, the coefficient on the volatility measure is highly significant in most cases. Consistent with the non-robustness findings of Levine and Reneult (1992), initial real GDP per capita, initial school enrollments and the measure of political instability, variables that have been significantly correlated with investment in some past studies, are not significant, but the share of trade in GDP is positive and highly significant. Regressions where the dependent variable is the private investment share over just the 1980-93 period give the same qualitative results on the linkage between volatility and private investment.

The regressions must be interpreted with caution. They are not tied to a structural model, nor do they establish a causal link between volatility and investment. They have not been subjected to the large number of sensitivity tests discussed in Levine and Reneult (1992). The exogeneity of at least one right-hand-side variable (REVCOUP) is questionable and there are econometric problems associated with using constructed measures of volatility as regressors. Despite these 
difficulties, we believe that the finding of a statistically significant negative partial correlation between volatility and private investment over the 1970-1993 period reinforces results obtained previously with data up through 1985 . It also calls for a theory of behavior under uncertainty that can deliver negative first-order effects of volatility on investment. We turn now to an exploration of the disappointment-averse utility-maximizing framework, a framework that yields the observed first-order effects from volatility. 


\section{Disappointment aversion utility}

We start with a discussion of the Allias paradox, as this paradox and other anomalies shaped the development of Gul's (1991) approach as well as other non-expected utility theories. 6 Next, we review Gul's formulation by considering the simplest case - a two-states-of-nature example. We use this example to explain the general approach, without attempting to deal with the more formal aspects of non-expected utilities.

The Allias paradox arises out of a situation where agents confront two pairs of gambles. The first pair of gambles compares a safe bet to a lottery that involves a small probability of a large disappointment relative to the safe bet. In the second pair of gambles, the agent confronts two lotteries that are rather similar in terms of the chance of disappointment. One offers marginally higher income in the "win" state at a marginally lower probability relative to the second lottery. For certain parameter values, agents frequently prefer the safe bet in the first pair of gambles, and the lottery that offers the higher income at a marginally lower probability in the second pair. These choices are inconsistent with maximizing expected utility. ${ }^{7}$ Gul suggested that these choices may be consistent for agents who exhibit aversion to disappointment. If the benchmark for

\footnotetext{
6 Another notable paradox is Ellsberg's Paradox, dealing with decision-making under Knightian uncertainty, where there is uncertainty about the probabilities of future events. Extension of the expected utility approach to deal with Knightian uncertainty can be found in Schmeidler (1989) and Gilboa (1987), applied by Dow and Werlang (1992) and Aizenman (1995).
}

${ }^{7}$ For example, in the first lottery pair the agent faces the choice a safe income [say $\$ 24,000$ with probability 1], versus a lottery that attaches a small probability of a large loss relative to the safe income [say income of $(\$ 27,500, \$ 24,000, \$ 0)$ with probabilities $(.33, .66, .01)$, respectively]. In the second lottery pair the agent must choose between lottery I offering $[(\$ 27,500, \$ 0)$ with probabilities $(.33, .67)$, respectively] versus lottery $I I$ offering $[(\$ 24,000, \$ 0)$ with probabilities $(.34, .66)$, respectively]. Typically, agents prefer the safe income in the first pair of lotteries, and the first lottery in the second pair. It is easy to confirm that the two choices are inconsistent with expected utility: the first implies $.33 u(27,500)+0.01 u(0)<.34 u(24,000)$, the second implies the opposite inequality. 
disappointment is the "certainty equivalent" income, agents may attach greater weights to circumstances where the realized income is below this benchmark. This leads to asymmetric weighting of states of nature and may explain the bias towards the safe bet exhibited in the Allias paradox. We turn now to a more formal description of Gul's approach.

The preferences of a disappointment-averse agent may be summarized by $[u(x), \beta]$, where $\mathrm{u}$ is a conventional utility function describing the utility of consuming $x,\left[\mathrm{u}^{\prime}>0, \mathrm{u}^{\prime \prime}<0\right]$, and $\beta \geq$ 0 is a parameter that measures the degree of disappointment aversion. 8 In the absence of risk, the agent's utility level is simply $u(x)$. Let us denote by $V(\beta)$ the expected utility of a disappointmentaverse agent (whose disappointment aversion rate is $\beta$ ). Suppose that the agent faces risky income $\left\{x_{s}\right\}$ in $n$ states of nature, $s=1, \ldots n$. Let $\mu$ denote the certain income that yields the same utility level as the risky income: $V(\beta)=u(\mu) .9$ The agent reveals disappointment aversion if he/she attaches extra disutility to circumstances where the realized income is below $\mu . \mathrm{A}$ convenient way to define $V(\beta)$ is

$$
V(\beta)=E(u(x))-\beta E[u(\mu)-u(x) \mid \mu>x]
$$

where $E$ is the expectation operator and $E[u(\mu)-u(x) \mid \mu>x]$ is the expected value of $u(\mu)-u(x)$, conditional on the realized consumption being below the certainty equivalent consumption. The term $E[u(\mu)-u(x) \mid \mu>x]$ measures the average "disappointment." It is the expected difference between the certainty equivalence utility and the actual utility in states of nature where the realized income is below the certainty-equivalence income. The disappointment-averse expected utility equals the conventional expected utility, adjusted downwards by a measure of disappointment aversion $(\beta)$ times the "expected disappointment."

${ }^{8} \mathrm{Gul}$ (1991) considered the more general case, where $\beta \geq-1$ and $u$ may be either convex or concave. We focus on the case where $\beta \geq 0$ because we restrict our attention to $u^{\prime \prime}<0$.

${ }^{9}$ I.e., the consumer is indifferent between the prospect of a safe income $\mu$ and risky income $\left\{x_{S}\right\}$ in $\mathrm{n}$ states of nature, $\mathrm{s}=1, \ldots \mathrm{n}$. 
We now restrict our attention to the simplest example -- two states of nature. Suppose that the agent will receive income $x$ in state $I(I=1,2)$, where $x_{1}>x_{2}$, with probabilities $(\alpha, 1-\alpha)$, respectively. Applying (1), the disappointment-averse expected utility is defined by:

$$
V(\beta)=\alpha u\left(x_{1}\right)+(1-\alpha) u\left(x_{2}\right)-\beta(1-\alpha)\left[V(\beta)-u\left(x_{2}\right)\right]
$$

Rearranging terms,

$$
V(\beta)=\alpha[1-(1-\alpha) \kappa] u\left(x_{1}\right)+(1-\alpha)[1+\alpha \kappa] u\left(x_{2}\right), \text { where } \kappa=\frac{\beta}{1+(1-\alpha) \beta}
$$

If the agent is disappointment-averse $(\beta>0)$, he attaches extra weight $(1-\alpha) \alpha K$ to "bad" states where he is disappointed (relative to the probability weight used in the conventional utility), and attaches a lesser weight $-\alpha(1-\alpha) \kappa$ to "good" states. Note that for $\beta=0, \mathrm{~V}$ is identical to the conventional expected utility.

Further insight regarding the welfare consequences of volatility can be gained with the help of Figure 1. Consider the case where the probability of facing each state is 0.5 , and let $u$ trace the dependency of utility on income, where income may fluctuate between $(1-\varepsilon)$ and $(1+\varepsilon)$. If $\beta=0$, the disappointment- aversion expected utility equals the conventional expected utility, and is obtained at the midpoint of $c d$, leading to second-order losses (i.e., losses proportional to $\varepsilon^{2}$ ). If $\beta>0$, the disappointment-aversion expected utility is obtained at the midpoint of $c^{\prime} d^{\prime}$. Notice that if $\beta>0$, the relevant utility is traced by the broken lines that transform $u$. The transformation increases the slope of $\mathrm{u}$ for states of nature where the agent is disappointed [ $\mathrm{x}<1$ in our example], and flattens the slope for $x>1$. Consequently, the modified utility is not differentiable at $x=1$; there is a "kink" at point $a$. This added concavity implies that volatility tends to lead to much larger welfare losses compared to the conventional case, as is depicted by the bold segment $a b$. From Figure 1 it is evident that the resultant loss is proportional to the degree of disappointment aversion, as bigger parameter values for $\beta$ increase the weight adjustment relative to the conventional case. To better appreciate this observation, we now turn to an examination of how disappointment aversion affects the demand for investment. 


\section{Volatility and investment}

Consider a two-period example, where the only risk is a random investment return. The utility is time separable, and the agent exhibits disappointment aversion in the presence of risk. In period one, the agent starts with an endowment of capital $(K)$ and some outside income $(Z)$. The first period production function is $\mathrm{f}(\mathrm{K})$, with $\mathrm{f}^{\prime}>0$ and $\mathrm{f}^{\prime \prime}<0$. Period two income is random and is given by $Z+f(K+I)(1+\lambda)$, where $\lambda$ is a random productivity shock, and $\mathrm{I}$ is the first period investment. We assume two states of nature - one with a positive productivity shock $[\lambda=\varepsilon]$ and the other with a negative productivity shock $[\lambda=-\delta]$ - with probabilities $[\alpha, 1-\alpha]$, respectively. We normalize the shocks such that the expected productivity shock is one:

$$
\alpha(1+\varepsilon)+(1-\alpha)(1-\delta)=1
$$

The consumer chooses investment I so as to maximize a disappointment-averse expected utility:

$$
\frac{V(\beta)}{1+\rho}+u(Z+f(K)-I)
$$

where $\rho$ is the subjective discount factor, and $V(\beta)$ is defined by (1) and (2). Applying (2), (3) and (4), the agent's problem is to maximize

(6)

$$
\left[\frac{\alpha}{1+(1-\alpha) \beta} u(Z+f(K+I)(1+\varepsilon))+\frac{(1-\alpha)(1+\beta)}{1+(1-\alpha) \beta} u(Z+f(K+I)(1-\delta))\right] \frac{1}{1+\rho}+u(Z+f(K)-I)
$$

Direct optimization leads to the following first-order condition: 
(7)

$$
\begin{aligned}
& {\left[\alpha(1+\varepsilon) u^{\prime}(Z+f(K+I)(1+\varepsilon))+(1-\alpha)(1+\beta)(1-\delta) u^{\prime}(Z+f(K+I)(1-\delta))\right] \frac{f^{\prime}(K+I)}{(1+\rho)[1+(1-\alpha) \beta]}} \\
& -u^{\prime}(Z+f(K)-I)=0
\end{aligned}
$$

Applying (7), we evaluate the impact of a mean-preserving change in volatility on the demand for investment: 10

(8)

$$
\left.\frac{d I}{d \varepsilon}\right|_{\varepsilon=0}=\frac{\beta \alpha}{1+(1-\alpha) \beta} \frac{u^{\prime}(Z+f(K+I))\left[1-R \frac{f(K+I)}{Z+f(K+I)}\right]}{\left[u^{\prime \prime}(f(K+I))\left(f^{\prime}(K+I)\right)^{2}+u^{\prime}(f(K+I)) f^{\prime \prime}(K+I)\right]+(1+\rho) u^{\prime \prime}(Z+f(K)-I)}
$$

where $\mathrm{R}$ is the coefficient of relative risk aversion, $R=-d \log u^{\prime}(x) / d \log x$. Thus,

$$
\text { (8a) } \operatorname{sign}\left[\left.\frac{d I}{d \varepsilon}\right|_{\varepsilon=0}\right]=-\operatorname{sign}\left[\beta\left[1-R \frac{f(K+I)}{Z+f(K+I)}\right]\right.
$$

Several observations can be made about equation (8):

10 Note that a mean-preserving change implies that $\frac{d \delta}{d \varepsilon}=\frac{\alpha}{1-\alpha}$. 
- The standard deviation of the productivity shock equals $\varepsilon \sqrt{\alpha /(1-\alpha)}$. Hence, (8) implies that volatility has first-order effects---and is proportional to the standard deviation-- as long as the agent is disappointment averse. ${ }^{11}$

- Increased volatility has a negative effect on investment as long as $\frac{Z}{f(K+I)}+1>R-$ as long as (one plus) the share of outside income relative to the risky income exceeds the coefficient of relative risk aversion. If the opposite inequality applies, volatility has first-order positive effects on investment.

- If $\beta=0$, agents maximize a conventional expected utility. In this case $\left.\frac{d I}{d \varepsilon}\right|_{\varepsilon=0}=0$, so that volatility has only second-order effects on investment. 12

- Even if the marginal utility of income is constant (so that $\mathrm{R}=0$ and agents are risk neutral in the conventional sense), volatility induces powerful negative effects on investment as long as the agent is disappointment averse. A higher coefficient of relative risk aversion and a lower share of outside income mitigate this effect.

To gain further insight, we turn to a simulation of the modified utility-maximizing model. We consider the case where

$$
\begin{aligned}
& f(K)=A K^{\gamma}, \quad 0<\gamma<1, \\
& u(x)=\frac{[x]^{1-R}+C}{1-R}, \quad R \geq 0
\end{aligned}
$$

11 Note that if the RHS of (8) is not zero, changes in $\varepsilon$ will impact investment proportionally [where the RHS of (8) is the proportionality factor]. Note also that the standard deviation of productivity shocks is proportional to $\varepsilon$. Combining these two facts we can infer that if $\beta \neq 0$, volatility effects are proportional to the standard deviation of shocks.

12 The second-order effects of volatility may be traced by taking a second-order Taylor expansion of the first-order condition (8). [See, for example, Newbery and Stiglitz (1981)]. In these circumstances the change in investment depends on the variance of the productivity shock. 
and $\mathrm{A}$ and $\mathrm{C}$ are constants. If the probability of each state is 0.5 , the FOC characterizing the optimal investment is:

(10)

$$
\frac{0.5 \gamma}{[1+0.5 \beta][1+\rho]}\left[Z+[K+I]^{\gamma}\right]^{-R}[K+I]^{\gamma-1}\left[(1+\varepsilon)^{\phi}+(1+\beta)(1-\varepsilon)^{\phi}\right]=\left[Z+A K^{\gamma}-I\right]^{-R}
$$

Figure 2 traces the impact of volatility (measured by $\varepsilon$ ) on investment. The simulation's calibration is done so that in the absence of volatility the optimal investment is $25 \%$ of the initial GDP. Notice that in the conventional case $(\beta=0)$, the demand for investment is almost independent of volatility for $\varepsilon<.15$. In contrast, volatility has first- order effects if $\beta>0$.

Further insight about the cost of volatility may be obtained by calculating the agent's willingness to pay for the elimination of volatility [i.e., the equivalent variation, denoted by EV]. Formally, EV is found by:

$$
\begin{aligned}
& {\left[\frac{\alpha}{1+(1-\alpha) \beta} u(Z+f(K+\tilde{I})(1+\varepsilon))+\frac{(1-\alpha)(1+\beta)}{1+(1-\alpha) \beta} u(Z+f(K+\tilde{I})(1-\delta))\right] \frac{1}{1+\rho}+u(Z+f(K)-\tilde{I})=} \\
& {\left[u\left(Z+f\left(K+\tilde{I}_{c}\right)\right)\right] \frac{1}{1+\rho}+u\left(Z-E V+f(K)-\tilde{I}_{c}\right)}
\end{aligned}
$$

where $\tilde{I}, \tilde{I}_{c}$ is the optimal investment in the regime with and without uncertainty, respectively. For the case where $\varepsilon=0.2$, we find that the cost of volatility is practically zero if the consumer is disappointment neutral, and $4.3 \%$ of GDP if $\beta=1$.

Figure 3 considers the case where the agent is risk neutral using the conventional definition (i.e., the case where the marginal utility of income is constant, $\mathrm{R}=0$ ). Even with a linear utility $u$, uncertainty has first-order adverse effects on investment as long as the agent is disappointment averse. The reason is that disappointment aversion causes the agent to treat 'good' and 'bad' states of nature asymmetically, independently of the concavity of the utility function. This asymmetric 
treatment creates a stronger non-linearity similar to the one described in Figure 1. The kink in the transformed disappointment-averse utility function appears even if the standard utility function (u) is linear due to risk neutrality. The stronger non-linearity introduced by disappointment aversion means that volatility induces first-order effects proportional to the product of the standard deviation times the degree of disappointment aversion, $\beta$. In contrast, with the standard neoclassical utility function, the effect of uncertainty typically hinges on a concavity argument, which in the absence of kinks produces only second-order effects (proportional to the variance of shocks). 


\section{Conclusions}

Our study uncovers a statistically significant negative correlation between volatility and private investment in a set of almost fifty developing countries and provides a possible interpretation of this result by invoking the disappointment aversion expected utility framework. Our treatment of 'volatility' encompasses various dimensions. Volatility may stem from fiscal or monetary factors, internal and/or external factors. As the various volatility measures tend to be positively correlated, we do not claim to identify a unique measure as the dominant source of volatility. Instead, we demonstrate that a number of different volatility measures can be used to show that volatility reduces private investment.

The disappointment aversion framework provides a useful framework for illustrating the first-order effects of volatility. It suggests that disappointment aversion should be taken seriously in trying to understand the reasons for a negative correlation between uncertainty and investment. No attempt, however, is made to claim that the disappointment-aversion framework is the only one that is consistent with the data. In fact, the work of Segal and Spivak (1990) suggests that similar effects may be produced by other versions of generalized expected utility. Furthermore, one might suspect that interactions between capital-market imperfections and disappointment aversion may magnify the adverse effects of volatility identified in our study. These potential interactions are of concern in dealing with developing countries, where limited integration with the global capital market may be the rule rather than the exception. Studying these interactions is left for further research. Nevertheless, it seems that stability of policies may be as important as the choice of the proper policies in promoting investment and growth. 


\section{References}

Abel, Andrew, 1983, Optimal Investment Under Uncertainty, American Economic Review (March), 73, 228-33.

, 1984, The Effects of Uncertainty on Investment and the Expected Long-Run Capital Stock, Journal of Economic Dynamics and Control (February), 7, 39-54.

1985, A Stochastic Model of Investment, Marginal Q and the Market Value of the Firm,

International Economic Review (June), 26, 305-22.

Aizenman, Joshua, 1995, Investment In New Activities and the Welfare Cost of Uncertainty, forthcoming, Journal of Development Economics.

Aizenman, Joshua and Nancy Marion, 1993, Policy Uncertainty, Persistence and Growth, Review of International Economics, Vol. 2, 145-163.

Barro, Robert, 1991, Economic Growth in a Cross Section of Countries, Quarterly Journal of Economics CVI, 407-444.

Caballero, Ricardo J., 1991, On the Sign of the Investment-Uncertainty Relationship, American Economic Review, Vol. 81, 279 - 288.

Dixit, Avinash K. and Robert S. Pindyck, 1994, Investment Under Uncertainty (MIT Press).

Dow, James and Sergio Ribeiro de Costa Werlang, 1992, Uncertainty Aversion, Risk Aversion, and the Optimal Choice of Portfolio, Econometrica, Vol. 62, 197-204.

Epstein, Larry G., 1992, Behavior under Risk: Recent Developments in Theory and Applications, Chapter 1 in Advances in Economic Theory: Sixth World Congress., Volume 1, Laffont-JeanJacques, ed. (Cambridge University Press), 1-63.

Gilboa, Itzhak, 1987, Expected Utility Theory with Purely Subjective Non-additive Probabilities, Journal of Mathematical Economics Vol. 16, 65-88.

Glen, Jack and Mariusz Sumlinski, 1995,Trends in Private Investment in Developing Countries 1995 , Discussion Paper No. 25, International Finance Corporation, World Bank. 
Gul, Farouk, 1991, A Theory of Disappointment Aversion, Econometrica, Vol. 59, No. 3 (May), 667 686.

Hartman, Richard, 1972, The Effects of Price and Cost Uncertainty on Investment, Journal of Economic Theory (October), 5, 258-66.

Hausmann, Ricardo, 1994, On the Road to Deeper Integration with the North: Lessons from Puerto Rico, manuscript, Inter-America Development Bank

Hausmann, Ricardo and Michael Gavin, 1995, "Macroeconomic Volatility in Latin America," manuscript, Inter-America Development Bank.

Harless D. W. and C. Camerer, 1994, "The Predictive Utility of Generalized Expected Utility," Econometrica, 1251-1290.

Levine, Ross and David Renelt, 1992, A Sensitivity Analysis of Cross-Country Growth Regressions, American Economic Review (September), 942-963.

Madarassy, Andrea and Guy Pfeffermann, 1992, Trends in Private Investment in Developing Countries, 1992 Edition, International Finance Corporation Discussion Paper No. 14, The World Bank.

Newbery, D. and J. Stiglitz, 1981, The Theory of Commodity Price Stabilization, Clarendon Press.

Pindyck, Robert S. and Andrès Solimano, 1993. "Economic Instability and Aggregate Investment," In NBER macroeconomics annual, Cambridge (MIT Press), 259-303.

Pratt, J. W., 1964, Risk Aversion in the Small and in the Large, Econometrica 32 (January), 122-36.

Ramey, Garey and Valerie A. Ramey, 1994, Cross Country Evidence on the Link Between Volatility and Growth, NBER working paper \# 4959.

Savage, L. J., 1954, Foundations of Statistics, New York: John Wiley \& Son.

Schmeidler, David, 1989, Subjective Probability and Expected Utility without Additivity, Econometrica, $57,571-587$

Segal, U. and A. Spivak, 1990, First-Order versus Second-order risk aversion, Journal of Economic Theory, Vol. 51, 111-25.

White, Halbert, "A Heteroskedasticity-Consistent Covariance Matrix Estimator and a Direct Test for Heteroskedasticity," Econometrica 48, 817-38. 


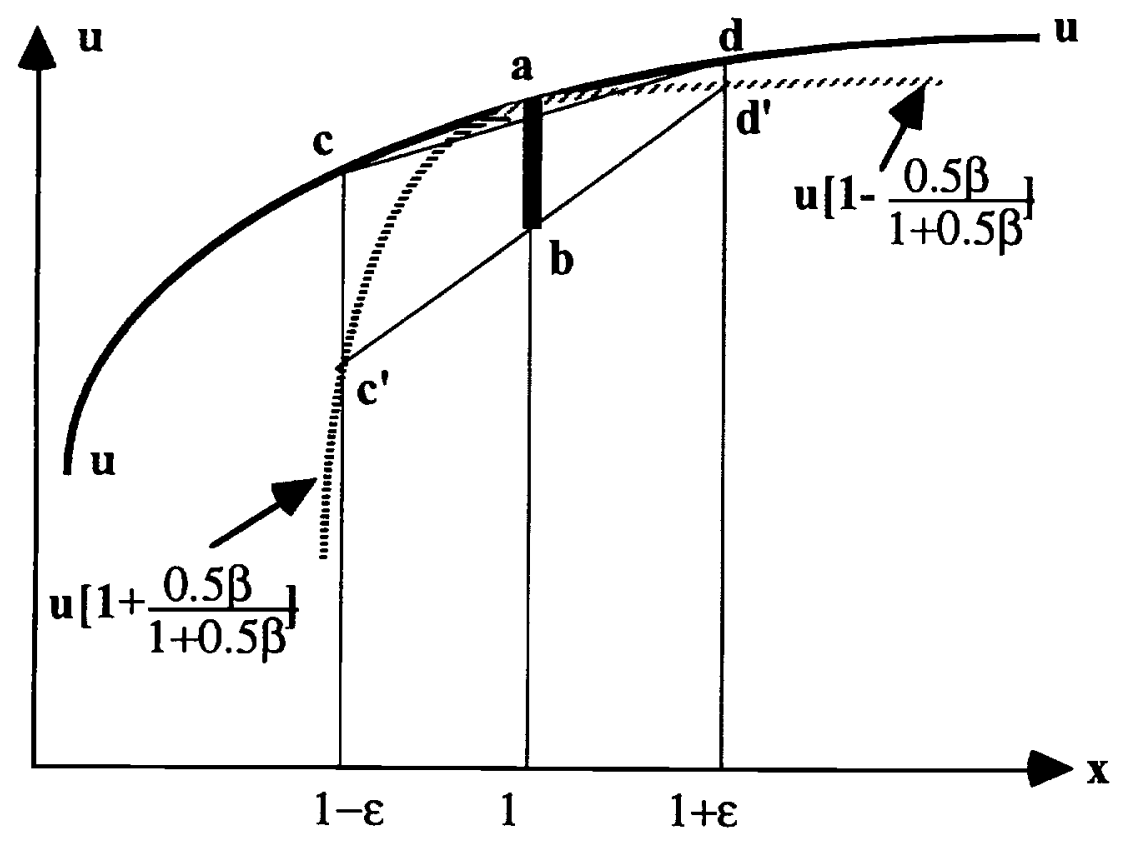

Figure 1

Volatility and disappointment aversion expected utility with two equal-probability states of nature 


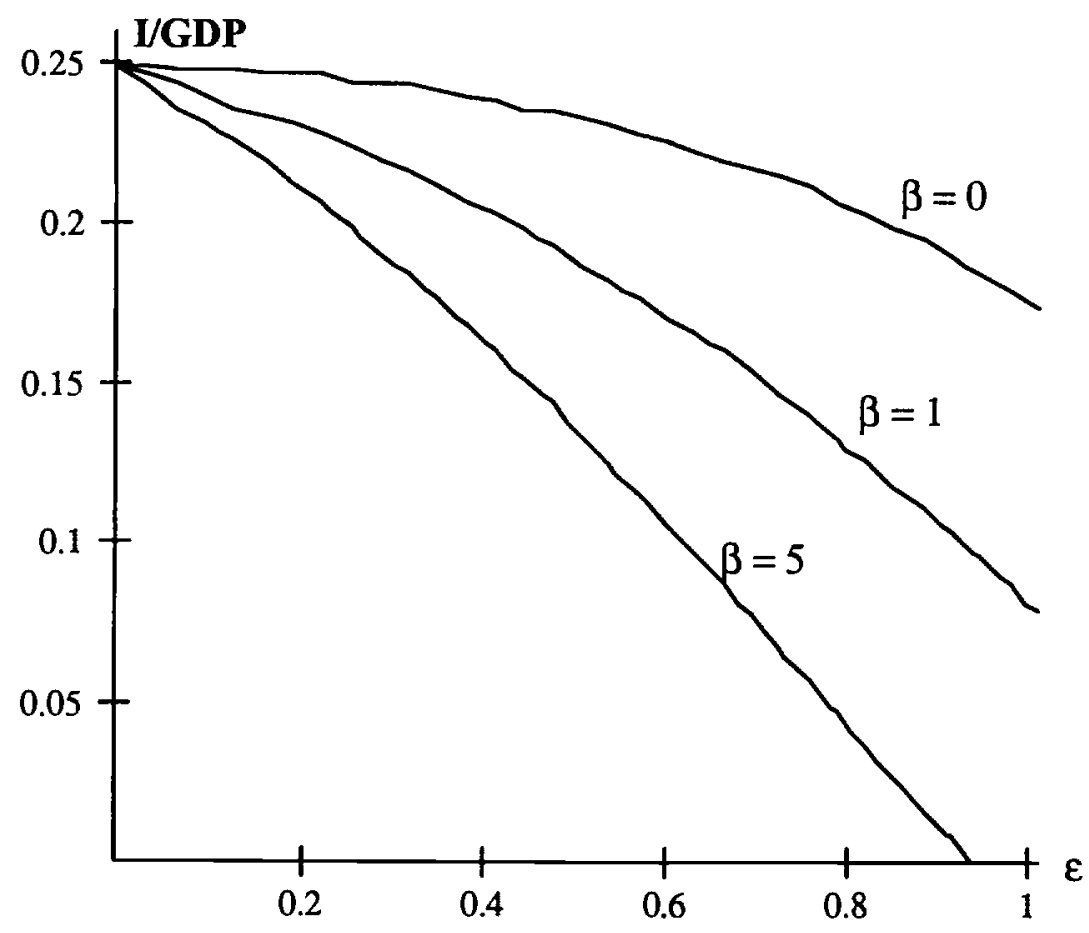

Figure 2

Volatility and investment:

$$
\rho=.05 \alpha=.5, \gamma=.7, \mathrm{R}=.5, \mathrm{~K}=1, \mathrm{~A}=7, \mathrm{Z}=10.87
$$




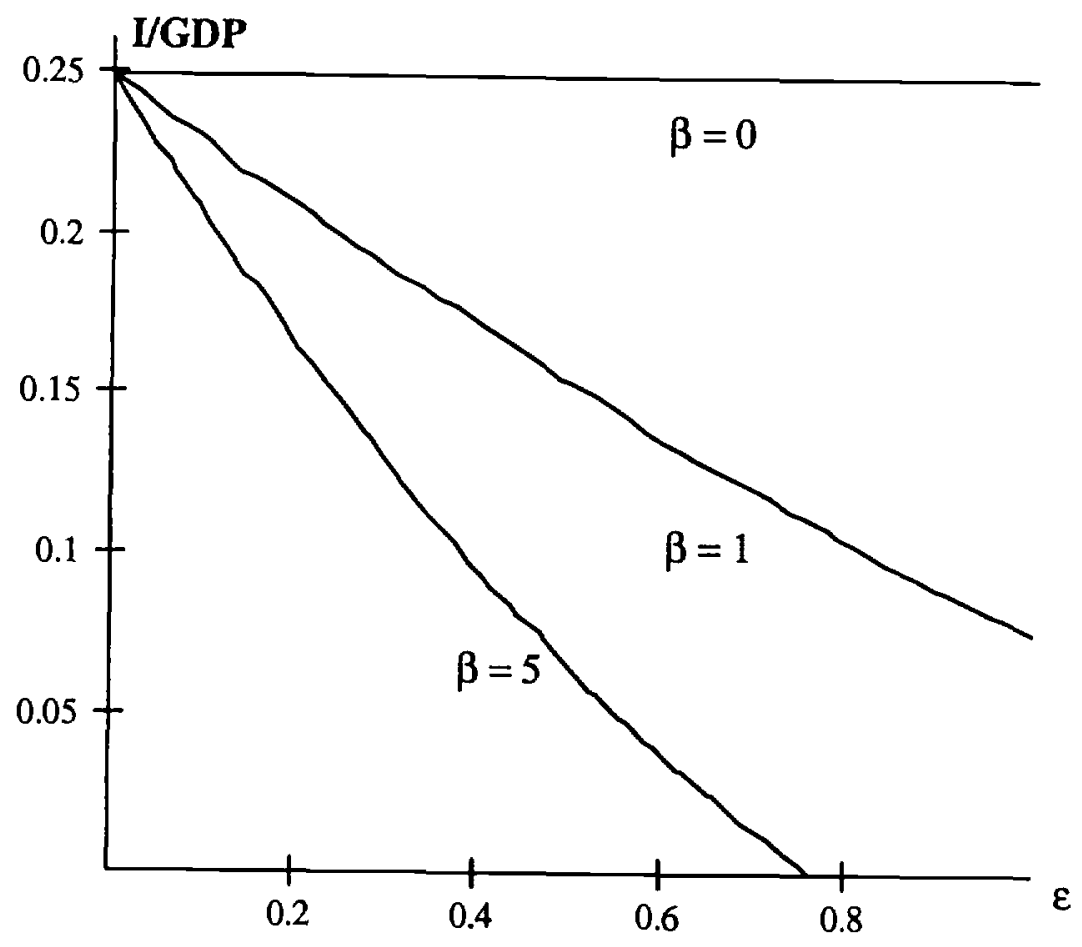

Figure 3

Volatility and investment with $R=0$ (constant marginal utility of income, so that agents are risk neutral in the conventional sense)

$$
\rho=.05 \alpha=.5, \gamma=.7, \mathrm{R}=0, \mathrm{~K}=1, \mathrm{~A}=4.64, \mathrm{Z}=10.87
$$


Table 1: Correlation Between Volatility and Private Investment

Volatility Measure

GOV

DEF

M1G

TOT

GGDP

INF

RER
Correlation

$-0.44$

$-0.39$

$-0.46$

$-0.15$

$-0.24$

$-0.08$

$-0.34$
t-Statistic

$-4.14$

$-1.42$

$-1.97$

$-0.68$

$-3.80$

\section{Notes:}

GOV = st. dev. from AR1 process of government consumption as share of GOP, 1970-92, mean value = $1.62 \%$;

$\mathrm{DEF}=$ st. dev. from AR 1 of fiscal deficit as share of GDP, 1970-92, mean value $=2.83 \%$;

$\mathrm{M} 1 \mathrm{G}=$ st. dev. from $\mathrm{AR} 1$ process of nominal $\mathrm{M} 1$ growth, mean value $=17.5 \%$;

TOT $=$ st. dev. from mean rate of change in terms of trade, $1970-92$, mean value $=15.01 \%$;

GGDP $=$ st. dev. from average real per capita GDP growth rate, $1970-92$, mean value $=4.41 \%$;

INF $=$ st. dev. from CPI inflation rate, 1990-92; mean value $136 \%$;

$\mathrm{RER}=$ st. dev. from average change in effective real exchange rate, mean value $=11.49 \%$.

Countries $=47$. Sample: Argentina, Bangladesh, Bolivia, Brazil, Chile, Colombia, Costa Rica, Cote D'voire, Dominican Republic, Ecuador, Egypt, El Salvador, Figi, Ghana, Guatemala, Guyana, Haiti, India, Indonesia, Iran, Kenya, Korea, Madagascar, Malawi, Malaysia, Mali, Mauritius, Mexico, Morocco, Nepal, Nigeria, Pakistan, Panama, Papua New Guinea, Paraguay, Peru, Philippines, Singapore, South Africa, Sri Lanka, Tanzania, Thailand, Tunisia, Turkey, Uruguay, Venezuela, Zimbabwe.

Sources: Penn World Tables, Version 5.6; World Bank World Tables; IMF International Financial Statistics; Inter-American Development Bank 
Table 2: Correlation Matrix for Volatility Measures

$\begin{array}{lllllllll} & \text { GOV } & \text { DEF } & \text { M1G } & \text { TOT } & \text { GGDP } & \text { INF } & \text { RER } & \text { REVCOUP } \\ \text { GOV } & 1.0 & & & & & & & \\ \text { DEF } & 0.62 & 1.0 & & & & & & \\ \text { M1G } & 0.70 & 0.63 & 1.0 & & & & & \\ \text { TOT } & 0.10 & 0.07 & 0.03 & 1.0 & & & & \\ \text { GGDP } & 0.22 & 0.05 & 0.20 & 0.27 & 1.0 & & & \\ \text { INF } & 0.02 & 0.55 & 0.15 & 0.02 & 0.08 & 1.0 & & \\ \text { RER } & 0.23 & 0.34 & 0.22 & 0.26 & 0.12 & 0.49 & 1.0 & \\ \text { REVCOUP } & -0.02 & 0.23 & -0.04 & 0.08 & -0.11 & 0.53 & 0.56 & 1.0\end{array}$


Table 3: Private Investment Regressions

\begin{tabular}{|c|c|c|c|c|c|c|c|}
\hline & 1 & 2 & 3 & 4 & 5 & 6 & 7 \\
\hline $\mathrm{n}$ & 47 & 47 & 47 & 47 & 47 & 46 & 44 \\
\hline c & $\begin{array}{l}9.3622^{* *} \\
(2.52)\end{array}$ & $\begin{array}{l}6.8833^{* *} \\
(2.10)\end{array}$ & $\begin{array}{l}10.654 * * \\
(2.50)\end{array}$ & $\begin{array}{l}6.8961 * * \\
(2.68)\end{array}$ & $\begin{array}{l}9.6790^{* * *} \\
(3.16)\end{array}$ & $\begin{array}{l}4.3142 \\
(2.76)\end{array}$ & $\begin{array}{l}8.0938 * * \\
(2.48)\end{array}$ \\
\hline RGDP70 & $\begin{array}{l}-0.2161 \\
(0.38)\end{array}$ & $\begin{array}{l}-0.31 \mathrm{E}-04 \\
(0.32 \mathrm{E}-3)\end{array}$ & $\begin{array}{l}0.3695 \\
(0.29)\end{array}$ & $\begin{array}{l}0.2080 \\
(0.57)\end{array}$ & $\begin{array}{l}0.2276 \\
(0.36)\end{array}$ & $\begin{array}{l}-0.0652 \\
(0.37)\end{array}$ & $\begin{array}{l}-0.0539 \\
(0.40)\end{array}$ \\
\hline PRIM70 & $\begin{array}{l}3.1769 \\
(2.72)\end{array}$ & $\begin{array}{l}4.6738 * * \\
(2.37)\end{array}$ & $\begin{array}{l}3.1100 \\
(2.43)\end{array}$ & $\begin{array}{l}4.5036 \\
(3.03)\end{array}$ & $\begin{array}{l}5.0631 * \\
(2.82)\end{array}$ & $\begin{array}{l}6.3589 * * \\
(3.14)\end{array}$ & $\begin{array}{l}7.0611^{* * *} \\
(2.95)\end{array}$ \\
\hline REVCOUP & $\begin{array}{l}0.7925 \\
(2.69)\end{array}$ & $\begin{array}{l}3.6493 \\
(2.23)\end{array}$ & $\begin{array}{l}0.7278 \\
(2.36)\end{array}$ & $\begin{array}{l}0.9951 \\
(2.77)\end{array}$ & $\begin{array}{l}0.2789 \\
(2.89)\end{array}$ & $\begin{array}{l}2.0628 \\
(2.99)\end{array}$ & $\begin{array}{l}4.8617^{*} \\
(2.60)\end{array}$ \\
\hline OPEN & $\begin{array}{l}0.0475^{* *} \\
(0.01)\end{array}$ & $\begin{array}{l}0.0544 * * \\
(0.74 \mathrm{E}-2)\end{array}$ & $\begin{array}{l}0.0512^{* * *} \\
(0.01)\end{array}$ & $\begin{array}{l}0.0410^{* *} \\
(0.01)\end{array}$ & $\begin{array}{l}0.0402 * * \\
(0.01)\end{array}$ & $\begin{array}{l}0.0420 * * \\
(0.01)\end{array}$ & $\begin{array}{l}0.37 \mathrm{E}-05 \\
(0.03)\end{array}$ \\
\hline VOLATLLITY & $\begin{array}{l}-1.386^{* *} \\
(0.42)\end{array}$ & $\begin{array}{l}-0.8392 * * \\
(0.15)\end{array}$ & $\begin{array}{l}-0.2778^{* *} \\
(0.05)\end{array}$ & $\begin{array}{l}-0.0931 \\
(0.08)\end{array}$ & $\begin{array}{l}-1.0114^{* *} \\
(0.44)\end{array}$ & $\begin{array}{l}-0.0011 \\
(0.002)\end{array}$ & $\begin{array}{l}-0.2764^{* *} \\
(0.08)\end{array}$ \\
\hline MEASURE & GOV & DEF & M1G & TOT & GGDP & INF & RER \\
\hline $\mathrm{R}^{2}$ & .36 & .43 & .47 & .27 & .32 & .26 & .28 \\
\hline $\bar{R}^{2}$ & .29 & .36 & .41 & .18 & .23 & .17 & .19 \\
\hline
\end{tabular}

Dependent variable is average percentage share of private investment in GDP over 1970-1993 $* *(*)$ indicates significance at $95 \%(90 \%)$ confidence interval. Standard errors are in parentheses and are heteroskedastic-consistent estimates.

Sources: Penn World Tables, Version 5.6; Glen and Sumlinski (1995); Madarassy and Pfeffermann (1992); World Bank World Tables; IMF International Financial Statistics; Inter-American Development Bank; Barro (1991) data. 